\title{
HYDROGEN PRODUCED BY SOLAR ENERGY AND THEIR USE AS CLEAN FUEL FOR POWER GENERATION IN A COMBINED CYCLE POWER PLANT
}

\author{
J. C. Restrepo ${ }^{\mathrm{a}}$, \\ O. J. Venturini ${ }^{a}$, \\ E. E. Silva ${ }^{a}$, \\ and L. A. Cortabarriab \\ ${ }^{a}$ Universidade Federal do Itajubá \\ Departamento de Engenharia Mecânica \\ Bairro Pinheirinho CP. 37500-903 \\ Itajubá, Minas Gerais, Brasil \\ jcrestrepol@hotmail.com \\ ${ }^{\mathrm{b}}$ Corporación Universidad de la Costa \\ Facultad de Ingeniería. \\ Barrio Alto Prado, Carrera 55 No 58-66 \\ Barranquilla, Atlántico, Colombia. \\ Received: April 02, 2016 \\ Revised: May 13, 2016 \\ Accepted: June 13, 2016 \\ $\mathrm{C}=$ Water concentration at the inlet, moles of gas $/ \mathrm{m}^{3}$. \\ $\mathrm{F}=$ molar production rate per gram of redox material, \\ $\mathrm{K}=$ Temperature-dependent reaction rate constant in \\ oxidation stage, $\mathrm{m}^{3} / \mathrm{moles} / \mathrm{min}$.
}

\begin{abstract}
The solar energy is one of the most promising energy sources expected for the future, due at their huge potential and the wide availability around the world. However, nowadays this important source of energy is not being harnessed or even addressed in their full potential. According to the last statements, it is important to develop solar energy conversion systems of high efficiency, as well as spreading its use in other forms besides the traditional systems of electric power generation or heating systems. For this reason, in this paper, it is explored the production of hydrogen through solar energy utilization, and the later electrical energy production by burning the produced hydrogen in a combined cycle power plant. The process was modelled for 3 MWe of electricity generation, and using the organic Rankine cycle. The main process for producing hydrogen from water using solar energy is based on a two steps redox thermochemical cycle, which has a theoretical conversion efficiencies of $54 \%$ at $1600 \mathrm{~K}$. It is expected that this paper could contributed to the development of ways to enable a better integration of the solar energy with the current electricity generation technologies, as well as to incentive the use of the hydrogen as a clean fuel.
\end{abstract}

Keywords: solar fuel, hydrogen production, ORC, combined cycle, renewable power generation

\section{NOMENCLATURE} moles/minute.

$\mathrm{Q}=$ Heat Flux kW.

$\mathrm{t}=$ time $(\mathrm{s})$.

\section{Greek symbols}

$\Psi=$ Instantaneous concentration of adsorbed oxygen, moles $\mathrm{O}_{2} / \mathrm{g}_{\text {redox }}$.

$\Phi=$ Instantaneous capacity of water splitting of the redox material, moles $\mathrm{H}_{2} / \mathrm{g}_{\text {redox. }}$.

$\eta=$ Efficiency.

\section{Subscripts}

Att $=$ Attenuation

Cosine $=$ Cosine .

Reflec $=$ Reflectance .

Shadowing $=$ Shadowing .

$\operatorname{tr}=$ Thermal Reduction.

ws $=$ Water splitting.

\section{INTRODUCTION}

With the imminent changes in the world weather and environment, mainly associated with the human activities and the fossil fuels consumption. In an addition to this phenomena, one can observe an increase in energy consumption related with the grow up of the human population and the higher energetic demand in the developing countries. This scenario is leading to the rise of the generation of global warming gases and a higher dependence to the fossil fuels.

Due the last statement it is important to achieve the optimal use of the renewable energy, looking for minimize the cost and effort to have its integration with the current infrastructure, and offering to the society several energetic carriers such as fuels, heat, electricity, etc.

One of the more promissory renewable resources is the solar energy, due the wide accessibility around the world and the infinity availability in human time lapse. Two different ways for taking advantage of the solar energy have been traditionally developed; the first one is transform the solar energy into heat, using the radiation heat transfer as the conversion path. The second one is the photovoltaic cell, which converts the incident solar radiation directly in electric energy using the photoelectric phenomena.

According with the last statement it would be extremely useful to have an energy source that it easily transformed into another. In this way, the best option to satisfy these constrains is use the thermal solar energy, because with different processes, it is 
possible obtain different energy carriers (e.g.). Using heat with heat machines one can obtain mechanical energy, and with the arrangement of electrical generator it is obtained electrical energy. In addition, it is possible the direct electrical energy generation using the thermoelectric effect. Beyond the last exposed technologies, is possible achieve a more valuable resource, as the concept of solar fuels, which is the use of the solar energy to convert a raw material (mainly water and/or carbon dioxide) into a fuel (pure hydrogen, or a syngas) being the hydrogen production the main focus. Many articles have been published about this topic, one of the principles is the paper published by Kodama (2003) and Martin et al. (2006).

\section{HYDROGEN PRODUCTION PATHS BY SOLAR ENERGY}

Several paths for solar hydrogen production have been developed; four different mechanism was used to produce hydrogen, as follows:

- Photoelectric effect.

- Photovoltaic panel with electrolysis.

- Heat with thermochemical cycles.

- Heat with thermal dissociation of water.

In the following it is shown the main paths for the hydrogen production, using the water as raw material, and using different technologies to achieve the solar energy such as, photovoltaic panel, photoelectrolysis cell and solar collectors.

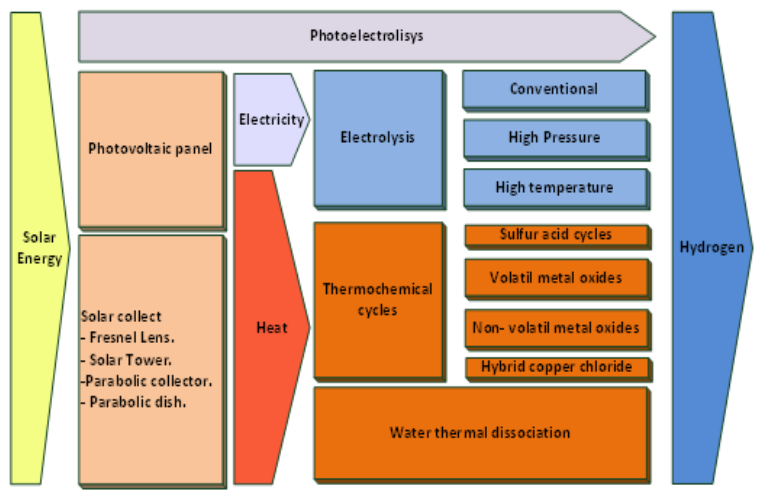

Figure 1. Mains paths for solar hydrogen production using water as raw material.

According with the research of Pregger et al. (2009), the more efficient process for the hydrogen production using solar energy is the thermochemical cycles using metal oxides as shown in the figure 2. Therefore, the process that will be used for the hydrogen production in this work is the metal oxide thermochemical cycle.

Many investigations have been done in this topic, but the more advanced is the project developed by Hydrosol, which test, in 2008, a pilot plant of 100
$\mathrm{kW}_{\text {th }}$ for hydrogen production Roeb et al.( 2011); the modelling of the use of SIC monolith reactors for hydrogen production Agrafiotis et al. (2007) and the characterization of different material and synthesis of the materials Martin et al. (2006).

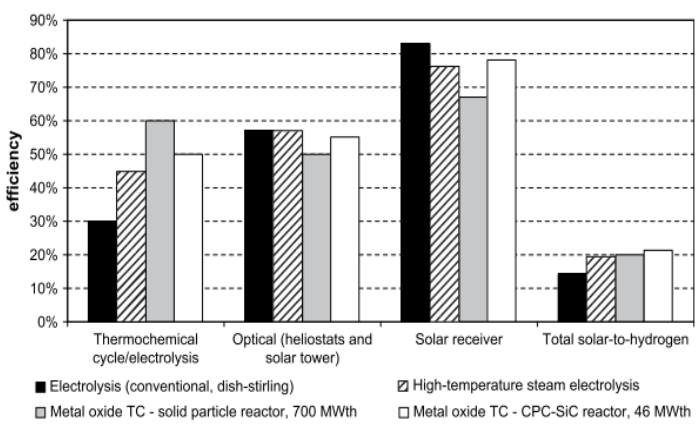

Figure 2. Efficiencies of solar hydrogen production under different process (Pregger et al., 2009).

The metal oxides thermochemical cycle is composed by just two stages. The first stage for the oxygen release, using an inert gas or vacuum for remove the oxygen from the metal oxide matrix, generally this stage occurs at the higher temperature and is endothermic. As result of this reaction, the metal oxide is free of oxygen or with lower valence level, and ready for the oxidation and initiate the hydrogen production stage. In this stage, steam and nitrogen enter in the matrix and the process begins. The metal oxide matrix is oxidized by the steam, allowing the hydrogen production (liberation).

The integration of the hydrogen with the current technologies is possible in different ways such as, power generation, hydrogen supply for different process and carbon recycling. The objective of this paper is to show the use of the hydrogen for power generation in a combined cycle for a power generation of 3 MWe, using as bottoming cycle the organic Rankine cycle, and as top cycle the Bryton cycle. Other remarkable concept beyond of the scope of this article is the possibility of using the hydrogen produced to recycle the carbon dioxide taken from another process and convert both of them, by means of a methanation reaction, into synthetic methane. Which can be supplied for the gas natural network or directly used as energy storage method, these topics have been deeply researched by Sterner (2009) and Giglio et al.(2015).

It will be considered two scenarios for the hydrogen burning in the gas turbines, this according the technical limitations of burning the hydrogen in the actual equipment. The first scenario will be the co-firing of the hydrogen with methane by $30 \%$ volume described by Wind, Güthe and Syed (2014). And one for long term scenario, according the research done by Siemens Bradley and Marra (2014), of co-firing up to $70 \%$ hydrogen by volume.

This paper will be developed in various sections, the first one related with the important 
parameters for the heliostat field and their energetic behaviour, the second section related with the hydrogen production in a solar reactor, and the third section related with the power generation.

\section{SOLAR ENERGY}

For the solar thermal only two solar thermal technologies are capable of reaching the high temperatures (above $1200 \mathrm{~K}$ ) required for the hydrogen production via thermochemical cycles s: which are parabolic dish (reach temperatures of 1500 ${ }^{\circ} \mathrm{C}$ Malagueta et al, (2014)) and solar tower (reach temperatures of $2000^{\circ} \mathrm{C}$ Kalogirou (2004)). Due to the high amount of energy required and the solar reactor layout, it was considered the solar tower technology. As reference was taken the following values as the average year efficiency for a heliostat solar field.

Table 1. Annual average efficiencies for a solar heliostat field, adapted from Stine and Harrigan, (1985).

Solar field efficiencies - Annual average

\begin{tabular}{|l|c|c|c|}
\hline Cosine loss & $77 \%$ & Reflectance & $90 \%$ \\
\hline Shadowing & $94 \%$ & Attenuation & $94 \%$ \\
\hline \multicolumn{2}{|c|}{ Total field efficiency } & $\mathbf{6 1 \%}$ \\
\hline
\end{tabular}

$$
\eta_{f}=\eta_{\text {Cosine } e} \eta_{\text {shadow }} \eta_{\text {reflec }} \eta_{\text {Att }}
$$

With the values presented on Table 1 it is possible to have a general view of the different losses of a heliostat field, allowing one to calculate the total field efficiency, according to Eq. (1).

Beyond the use of the solar collectors as energy concentrator, in the Hydrosol project the heliostat was used also as a way for controlling the process. Due to the different energy requirements during the reduction and oxidation stages, the energy input for the reactor is controlled by the number of heliostat focused on it. In this way, the better arrangement for a quasi-continuous hydrogen production is synchronizing two reactors, in such form that while the first is in the reduction stage the second one is in oxidation stage, switching the stages when the process finish.

\section{SOLAR HYDROGEN REACTOR.}

For the reactor model it was used the experimental information about the behavior of thermal reduction and oxidation process based in the $\mathrm{NiFe}_{2} \mathrm{O}_{4}$ metal oxide Agrafioti et al, (2009), supported in a SIC matrix. The equation was developed considering the experimental behavior of the hydrogen production and the release of oxygen, also taking in account the degradation of the matrix across different cycle numbers.

$$
\begin{gathered}
F_{H 2}=k_{W S} \phi C_{H 2 O} e^{-k_{W S} C_{H 2 O} t}, \\
F_{O 2}=k_{t r} \psi e^{-k_{t r} \psi t},
\end{gathered}
$$

Using equations (2) and (3) it is possible to describe the production of hydrogen and oxygen, and to dimension the required reactors for the hydrogen production. For the develop of this paper is required the design of solar reactor composed by matrix based in $\mathrm{NiFe}_{2} \mathrm{O}_{4}$ metal oxide, this due the necessity to know the behavior of the solar reactor under different solar fluxes and this implication in the hydrogen production. Therefore will be used as reference information, the reactors developed for the Hydrosol project, since this is the first plant in the world for metal oxides thermochemical cycles Roeb et al, (2009). The information took from the reference, is the matrix material properties and their geometry. For this paper, it was considered am arrangement of nine matrix materials in SIC with $146 \mathrm{mmX} 146 \mathrm{mmX} 60 \mathrm{~mm}$, being the same arrangement used in the Hydrosol $100 \mathrm{kWth}$ plant Roeb et al, (2011).

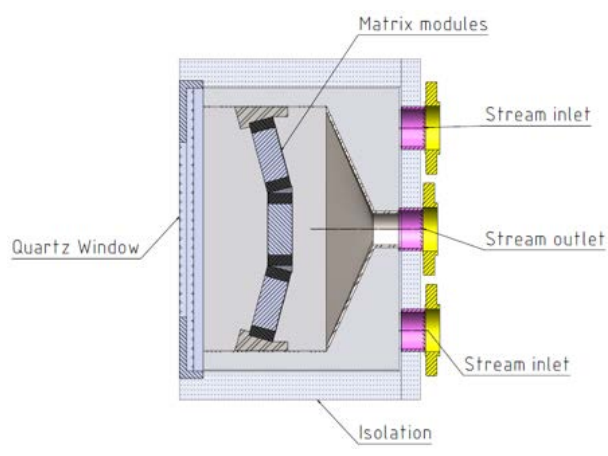

Figure 3. Predesign of solar reactor.

One of the most important parameters during the oxidation and reduction cycles is keep the temperature for each stage, for this reason and having in consideration the complexity of the phenomena and the diverse heat transfer forms involved in the reactor (conduction, convection and radiation). Was simulated the thermal response of the reactor, with a 3D CFD code floworks, being this code part of the CAD suite Solidworks. The main objective of this simulation is find the working temperature for each stage in the matrix, under different solar powers, as boundary conditions was used the incoming solar flux and the mass flow inside the reactor, considering the different temperatures and streams for each cycle stage. Was used k-epsilon as turbulence model.

One of the most important parameters during the oxidation and reduction cycles is keep the temperature for each stage, for this reason and having in consideration the complexity of the phenomena 
and the diverse heat transfer forms involved in the reactor (conduction, convection and radiation). Was simulated the thermal response of the reactor, with a 3D CFD code floworks, being this code part of the CAD suite solidworks. The main objective of this simulation is find the working temperature for each stage in the matrix, under different solar powers, as boundary conditions was used the incoming solar flux and the mass flow inside the reactor, considering the different temperatures and streams for each cycle stage. Was used k-epsilon as turbulence model.

In the figure 4 , it is represented the simulation result for the temperature distribution inside the reactor for a solar power of $40 \mathrm{~kW}$, showing the average temperature of the matrix and the inlet temperature. For understand the behaviour of the reactor under different values of solar power and the response of the temperatures under this change, it was made two plots showing the variation of the temperature related with the sun power for the two stages of the cycle, oxidation and reduction described in the figure 5 . Where the solar power consumption are concordant with the field behaviour tested by the $100 \mathrm{kWth}$ solar hydrogen production plant Roeb et al, (2011).

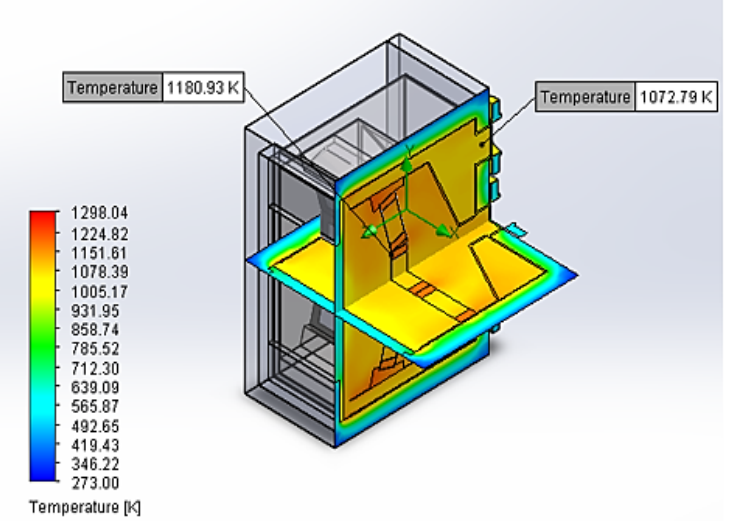

Figure 4. Temperature distribution for a solar power of $40 \mathrm{~kW}$ in oxidation stage.

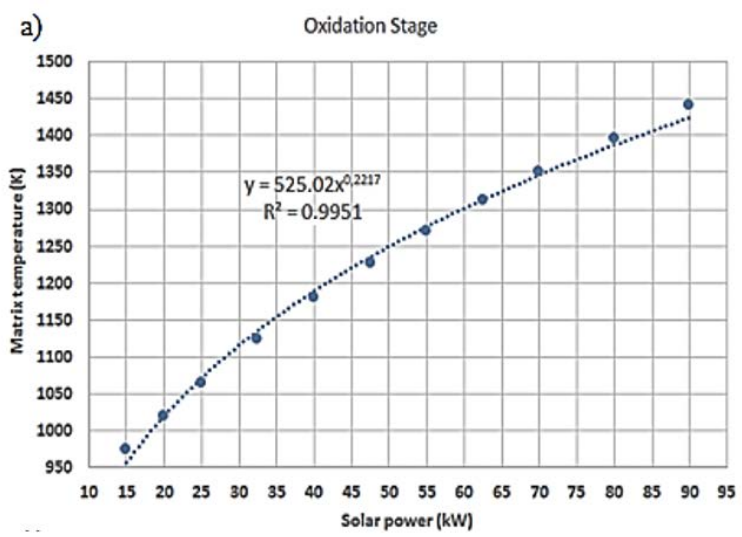

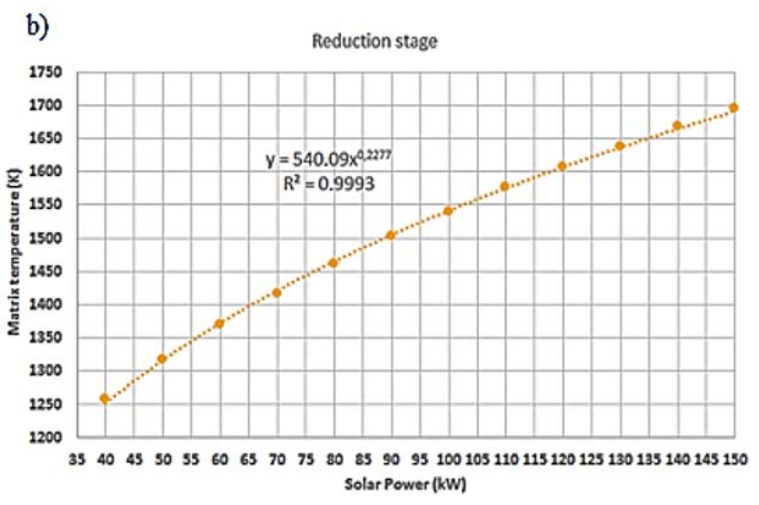

Figure 5. Matrix Temperature vs Solar Power, a) Oxidation stage, b) Reduction stage.

Knowing the solar energy input and the hydrogen yield described by the equations (2) and (3), it is possible to calculate the behavior of the cycle as showed in the figure 6 . It is interesting to notice the deviation of the hydrogen production between the first and the second oxygen cycle, due the degradation of the matrix and the irreversibility in the process.

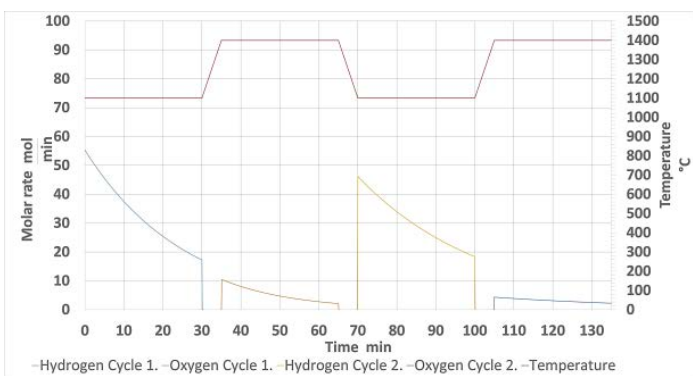

Figure 6. Hydrogen and oxygen production.

Therefore, the global mass of hydrogen production per cycle, i.e., the hydrogen production yield, is showed on Figure 6. The temperature of the reduction stage is fixed, because at higher temperatures of $1400 \mathrm{~K}$ the nickel enclose starts to degrade. For this reason, the plot is in function only of the oxidation stage temperature.

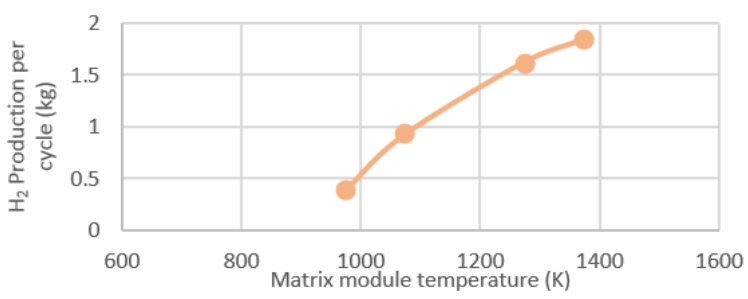

Figure 6. Mass production in function of the oxidation stage temperature.

$$
\eta_{\text {reator }}=\frac{m_{\mathrm{H} 2} L H V_{H 2}}{\dot{Q}_{\text {Oxidation }} t_{\text {stage }}+\dot{Q}_{\text {reduction }} t_{\text {stage }}},
$$




$$
\eta_{\text {STH } 2}=\frac{m_{H 2} L H V_{H 2}}{\dot{Q}_{\text {Oxidation }} t_{\text {stage }}+\dot{Q}_{\text {reduction }} t_{\text {stage }}} \eta_{f} \text {, }
$$

The efficiency of the solar reactor and the whole process was described in the Eq. (4) and Eq. (5), relating the solar energy input and the energy stored in the hydrogen and the efficiency of the solar field.

The efficiencies obtained for the different reduction temperatures is shown in the next figure, describing the efficiencies for the solar reactor and for the whole process.

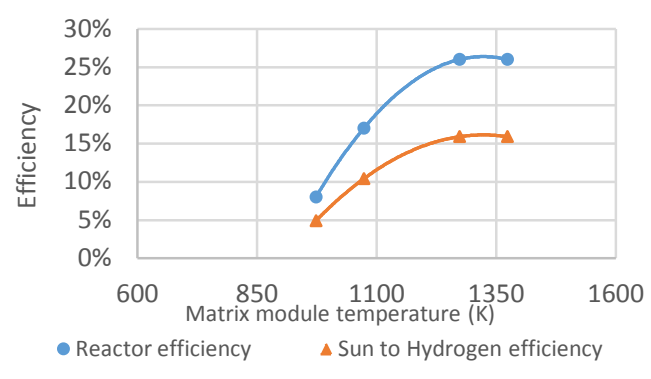

Figure 7. Efficiencies of the processes.

\section{POWER GENERATION}

To achieve a good thermal efficiency at lower power, it was used a combined cycle composed of a gas turbine and an Organic Rankine Cycle. To have a common frame with the currents technologies it was chosen the best gas turbines in terms of efficiency from the Gas turbine World 2010 GTW Handbook Farmer (2010), listed below.

Table 2. Commercial gas turbines bellow of $3 \mathrm{MW}$ adapted from Farmer (2010).

\begin{tabular}{|c|c|c|c|c|}
\hline Brand & $\begin{array}{l}\text { Pratt \& } \\
\text { Whitney }\end{array}$ & $\begin{array}{l}\text { OPRA } \\
\text { Turbin } \\
\text { e }\end{array}$ & $\begin{array}{l}\text { ZM } \\
\text { Turbine } \\
\text { s }\end{array}$ & $\begin{array}{l}\text { Mitsui } \\
\text { Engineerin } \\
\text { g }\end{array}$ \\
\hline Model & ST18A & $\begin{array}{l}\text { OP16- } \\
3 \mathrm{~A}\end{array}$ & $\begin{array}{l}\text { UGT } \\
2500\end{array}$ & SB15 \\
\hline Power kW & 1961 & 1910 & 2670 & 2720 \\
\hline Efficiency & $30.4 \%$ & $26.9 \%$ & $26.7 \%$ & $25.6 \%$ \\
\hline $\begin{array}{l}\text { Pressure } \\
\text { ratio }\end{array}$ & 14 & 6,7 & 12 & 10 \\
\hline $\begin{array}{l}\text { Mass flow } \\
\mathrm{kg} / \mathrm{sec}\end{array}$ & 8 & 8.7 & 16.5 & 14.5 \\
\hline Speed RPM & 18900 & 26000 & 3000 & 13070 \\
\hline $\begin{array}{l}\text { Exhaust } \\
\text { temperatur } \\
\mathrm{e}^{\circ} \mathrm{C}\end{array}$ & 532.2 & 555.6 & 460 & 491.1 \\
\hline
\end{tabular}

These turbines are designed to burn natural gas. The strategies and changes in operation and design for burn hydrogen is discussed by Chiesa, et al (2005). In the combined cycle proposed these turbines will be arranged as the top cycle for the combined cycle, and for the bottoming cycle it will be used an ORC with the following working fluids and parameters.

Table 3. Power generation under different co-firing scenario.

\begin{tabular}{|c|c|c|c|}
\hline Working Fluid & Toluene & Cyclopentane & Decane \\
\hline $\begin{array}{c}\text { Max Pressure } \\
\text { (Bar) }\end{array}$ & 35.76 & 40 & 18 \\
\hline $\begin{array}{c}\text { Max } \\
\text { temperature } \\
\begin{array}{c}\left.\mathbf{(}^{\circ} \mathbf{C}\right) \\
\text { Sat. Pressure } \\
\text { (kPa) }\end{array}\end{array}$ & 300 & 230 & 300 \\
\hline $\boldsymbol{\eta}_{\text {turbine (\%) }}$ & 85 & 40 & 5 \\
\hline $\boldsymbol{\eta}_{\text {pump (\%) }}$ & 75 & 85 & 85 \\
\hline & & 75 & 75 \\
\hline
\end{tabular}

Hence with this values it was calculated the power generated by the combined cycle and their efficiency, what is shown in the Figure (8).

With these results it is possible to calculate the amount of hydrogen required for the combined cycle and the number of solar reactors required for suppling this hydrogen. The power plant was conceived for the peak energy hours, when the solar power is not available and therefore the hydrogen produced for one day must be enough for the power plant operation during the estimated time, in this case, a period of 3 hours was considerate. Due to the limitation of burning pure hydrogen in gas turbines, it will be considered its burning with natural gas as explained in the previous section.

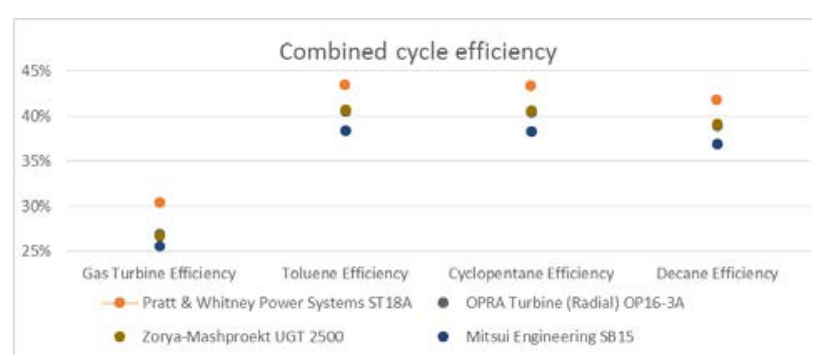

Figure 8. Combined cycle efficiencies for different working fluids.

The table 4 summarizes all the information of the hydrogen production and the power generated for the combined cycle. Where was calculated the hydrogen mass rate required for the two scenarios (hydrogen and methane co-firing in $30 \%$ and $70 \%$ by volume), and their necessary number of solar reactors to produce this amount of hydrogen according with the behavior seeing in the figure 4 . For the hydrogen production was taken a period of 8 hours, based in the average solar hours in Brazil, according with the Brazilian solar atlas ANEEL (2005).

Table 4. Power generation under different co-firing scenario.

\begin{tabular}{l|l|l|l|l} 
Brand & $\begin{array}{l}\text { Pratt \& } \\
\text { Whitney }\end{array}$ & $\begin{array}{l}\text { OPRA } \\
\text { Turbine }\end{array}$ & $\begin{array}{l}\text { ZM } \\
\text { Turbines }\end{array}$ & $\begin{array}{l}\text { Mitsui } \\
\text { Engineering }\end{array}$ \\
\hline
\end{tabular}




\begin{tabular}{|l|c|c|c|c|}
\hline Model & ST18A & OP16-3A & $\begin{array}{l}\text { UGT } \\
2500\end{array}$ & SB15 \\
\hline $\begin{array}{l}\text { Power } \\
\text { Turbine } \\
\text { kW }\end{array}$ & 1961 & 1910 & 2670 & 2720 \\
\hline $\begin{array}{l}\mathbf{H}_{2} \text { mass } \\
\text { rate kg/s } \\
\text {-30\% }\end{array}$ & 0.0103 & 0,0113 & 0.016 & 0.017 \\
\hline $\begin{array}{l}\mathbf{H}_{2} \text { mass } \\
\text { rate } \mathbf{k g} / \mathbf{s}\end{array}$ & 0.0518 & 0,057 & 0.0803 & 0.0853 \\
\hline $\mathbf{- 7 0 \%}$ & & 12 & 16 & 18 \\
\hline $\begin{array}{l}\text { Solar } \\
\text { reactors } \\
\text { for 30\% } \\
\text { co-firing }\end{array}$ & 10 & & & \\
\hline $\begin{array}{l}\text { Solar } \\
\text { reactors } \\
\text { for 70\% } \\
\text { of co- } \\
\text { firing }\end{array}$ & 52 & 56 & 80 & 84 \\
\hline $\begin{array}{l}\text { Cyclope } \\
\text { ntane } \\
\text { Power } \\
\text { kW }\end{array}$ & 2791.4 & 2871 & 4064.4 & 4068.2 \\
\hline
\end{tabular}

These values were calculated under the best scenario for the hydrogen yield as seen in the figure 5 and 6, which is $1673 \mathrm{~K}$ for the reduction stage and $1373 \mathrm{~K}$ for the oxidation stage. For the Organic Rankine cycle was chosen the Cyclopentane as working fluid due at good performance and the higher safety compared with the toluene.

\section{CONCLUSIONS}

Using the solar production of hydrogen is possible to have an integration between the solar energy and the currents technologies of power generation and use it in co-firing with fossil fuels, allowing the decrease of the generation global warming gases and the dependence for the fossil fuels. Beyond this, the paper explores the concept of solar fuels and the thermochemical cycles, one of the most promissory technologies for the thermal solar power.

In the figure 6 is possible see a strongly dependence of the hydrogen yield with the temperature. With higher temperatures is possible to obtain higher disassociate rates, improving the hydrogen yield. However, the increase of this temperature produces some problems related with the degradation of the matrix, and e thermal losses in the reactor. Therefore, more research must be done looking for improving the water splitting in the reactor through better matrix materials and improve the thermal performance of the solar reactor.

One of the advantages of use this technology is the elimination of the requirement of heat storage and burners for the solar thermal plants, where these technologies were required for the electrical energy generation without solar resource. Looking for reduce the plant cost the use of these technologies must be avoided. Therefore, in this works the energy storage was done through the hydrogen production, which can be used at any part of the day.

\section{ACKNOWLEDGMENTS}

The authors would like to acknowledge FAPEMIG - Fundação de Amparo à Pesquisa do Estado de Minas Gerais, CNPq - Conselho Nacional de Pesquisa and CAPES - Coordenação de Aperfeiçoamento de Pessoal de Nível Superior, for the financial support that allowed us to perform this study.

\section{REFERENCES}

Agrafioti, C., Zygogianni, A., Pagkoura, C., Kostoglou, M., and Konstandopoulos, A. 2009, Hydrogen Production via Solar-Aided Water Splitting Thermochemical Cycles with Nickel Ferrite: Experiments and Modeling, IFAC Proceedings Volumes (IFAC-PapersOnline), Vol. 7, No. 1, pp. 405-410.

Agrafioti, C., Zygogianni, A., Pagkoura, C., Kostoglou, M., Konstandopoulos, A., and Lorentzou, S., 2007, Hydrogen Production in Solar Reactors Catalysis Today, Vol. 127, No. 1-4, pp. 265-277.

Algieri, A., and Morrone, P., 2013, Energetic Analysis of Biomass-Fired ORC Systems for MicroScale Combined Heat and Power (CHP) Generation. A possible Application to the Italian Residential Sector, Applied Thermal Engineering, Vol. 21, No. 2, pp. 751-759.

ANEEL, 2005, Atlas de Energia Eletrica do Brasil, ANEEL.

Bradley, T., and Marra, J., 2014, Advanced Hydrogen Turbine Development Update, Proceedings of ASME Turbo Expo 2012, pp. 1-9.

Chiesa, P., Lozza, G., and Mazzocchi, L., 2005, Using Hydrogen as Gas Turbine Fuel, Journal of Engineering for Gas Turbines and Power, Vol. 127, No. 1, pp. 73-81

Farmer, R., 2010, Gas Turbine World 2010 GTW Handbook, Southport, Pequot.

Giglio, E., Lanzini, A., Santarelli, M., and Leone, P., 2015, Synthetic Natural Gas via Integrated High-Temperature Electrolysis and Methanation: Part I, Energy performance Journal of Energy Storage, Vol. 1, pp. 22-37.

Kaloguirou, S., 2004, Solar Thermal Collectors and Applications, Progress in Energy and Combustion Science, Vol. 30, pp. 231-295.

Lai, N., Wendland, M., and Fischer, J., 2011, Working Fluids for High-Temperature Organic Rankine Cycles, Energy, Vol.. 36, No. 1, pp. 199211.

Malagueta, D., Szklo, A., Soria, R., Dutra, R., and Borba, B., 2014, Potential and Impacts of Concentrated Solar Power (CSP) Integration in the Brazilian Electric Power System, Renewable Energy, Vol. 68, pp. 223-235.

Pregger, T. Graf, D., Krewitt. W., Sattler. C., Roeb. M., and Moller, S., 2009, Prospects of Solar Thermal Hydrogen Production Processes, 
International Journal of Hydrogen Energy, Vol. 34, No. 10, pp. 4256-4267.

Roeb, M., Neises, M., Sack, J., Rietbrock, P., Monnerie, N., Dersch. J. S., and Sattler, C., 2009, Operational Strategy of a Two-Step Thermochemical Process for Solar Hydrogen Production, International Journal of Hydrogen Energy, Vol. 34, No. 10, pp. 4537-4545.

Roeb, M., Monnerie, N., Sattler, C., Kluser, R., Oliveira, L., Konstandopoulos, A., Agrafioti, C., Zaspalis, V., Nalbandian, L., Steele, A., and Stobbe, P., 2006, Solar Hydrogen Production by a Two-Step Cycle Based on Mixed Iron Oxides, Journal of Solar Energy Engineering, Vol. 128, No. 2, pp. 125.

Roeb, M., Neises, M., Sack, J., Rietbrock, P., Sattler, C., and Rietbrock, P., 2011, Test Operation of a $100 \mathrm{~kW}$ Pilot Plant for Solar Hydrogen Production from Water on a Solar Tower, Solar Energy, Vol. 85, No. 4, pp. 634-644.

Sterner, M., 2009, Bioenergy and Renewable Power Methane in Integrated 100\% Renewable Energy Systems, Doctoral Thesis, Kassel University, Kassel.

Stine, W., and Harrigan, R., 1985, Solar Energy Fundamentals and Design, John Wiley \& Sons, New Jersey, $1^{\text {st }}$ edition.

Wind, T., Güthe, F., and Syed, K., 2014, CoFiring of Hydrogen and Natural Gases in Lean Premixed Conventional and Reheat Burners (Alstom GT26), in: ASME Turbo Expo 2014, pp. 1-9. 